\section{Clinica Ciruirgica \\ IMPACTO DO NÚMERO DE LINFONODOS RETIRADOS NA SOBREVIDA APÓS GASTRECTOMIA POR CÂNCER GÁSTRICO}

Os autores estudaram aproximadamente 4.000 pacientes submetidos a gastrectomia por câncer gástrico no período de 1973 a 1999. Foram considerados somente os casos cuja cirurgia foi curativa (sem margens cirúrgicas comprometidas, sem doença residual e sem metástases em outros órgãos). Foram excluídos do estudo todos os pacientes que receberam quimio e/ou radioterapia pré ou pós-operatória. Trata-se de estudo multicêntrico realizado em pacientes de 14 centros de oncologia dos Estados Unidos, englobando um total de 65.560 doentes diagnosticados com câncer de estômago. Foi analisada a sobrevida após a cirurgia, correlacionada com o número de linfonodos ressecados em quatro subgrupos de acordo com a classificação TNM: TI/2N0, TI/2NI, T3N0 e T3NI.

Os resultados mostraram que quanto maior o número de linfonodos ressecados, maior era o índice de sobrevida em todos os subgrupos estudados. A sobrevida de 5 anos se somente um linfonodo houvesse sido ressecado por paciente alcançaria: $56 \%$ no grupo $\mathrm{TI} / 2 \mathrm{~N} 0,35 \%$ no $\mathrm{TI} /$ $2 \mathrm{NI}, 29 \%$ no T3N0 e $13 \%$ no T3NI. Para cada 10 linfonodos extras retirados por paciente, havia um aumento de $7,6 \%$ no subgrupo $\mathrm{TI} / 2 \mathrm{~N} 0,5,7 \%$ no $\mathrm{TI} / 2 \mathrm{NI}, \mathrm{I}$ I \% no T3N0 e 7\% no T3NI; e esse aumento da sobrevida continuou acontecendo mesmo acima dos 40 linfonodos extirpados. Na média, houve um aumento de $0,8 \%$ na sobrevida a cada linfonodo dissecado a mais, considerando o cut point de um linfonodo extirpado por paciente.

\section{Comentário}

Os benefícios da linfadenectomia ampliada já foram exaustivamente demonstrados por estudos japoneses, chineses, coreanos e europeus. Somente os estudos americanos (com raras exceções) questionavam a eficiência da linfadenectomia estendida no tratamento do câncer gástrico. Vemos com muita satisfação que um estudo de porte e multicêntrico norte-americano finalmente reconhece a importância da linfadenectomia no tratamento do câncer de estômago. Acreditamos que a linfadenectomia D2 ou ampliada (retirada dos linfonodos até $6 \mathrm{~cm}$ do tumor primário) deva ser rotineira em toda cirurgia que pretende ser curativa no tratamento do adenocarcinoma gástrico.

Elias JiRJoss Illas

Refêrencia

Smith DD, Schwarz RR, Schwarz RE. Impact of total lymph node count on staging and survival after gastrectomy for gastric cancer: data from a large us-population database. J Clin Oncol 2005;23:7 I I 4-24.

\section{Pediatria \\ CRESCIMENTO DE CRIANCGAS COM ARTRITE JUVENIL TRATADAS COM ESTERÓIDE}

Foram avaliados retrospectivamente 24 pacientes com artrite juvenil idiopática (AJl) durante a infância tratados com esteróides. Houve uma perda de altura significativa de mais de dois desvios padrão durante os primeiros anos de doença, que se correlacionaram positivamente com a duração do tratamento com prednisona. Após a descontinuação da medicação, $70 \%$ dos pacientes fizeram catch-up, mas $30 \%$ persistiram com perda estatural. Sua altura final foi correlacionada fortemente com a altura média ao final do tratamento, e era muito diferente quando comparada ao grupo que fez catch-up. Os autores publicaram anteriormente os efeitos benéficos sobre o crescimento e a composição corpórea de um ano de tratamento com $\mathrm{GH}$ num grupo de 14 pacientes com All que haviam recebido corticóide e GH. Esses pacientes foram novamente tratados por três anos, o que aumentou sua velocidade de crescimento, mas tiveram pouco efeito sobre o SDS de altura, sugerindo que tais crianças permanecerão baixas quando adultas. Iniciar GH mais cedo pode evitar deterioração do crescimento e as complicações metabólicas induzidas por corticoterapia crônica.

\section{Comentário}

Várias situações clínicas exigem tratamento prolongado com glicocorticóides, o que afeta a estatura final. Várias tentativas (bisfosfonatos, suplementação de cálcio e vitamina $D, G H)$ têm sido feitas para minimizar tal desfecho indesejável. Faltam ainda estudos em que o uso de $\mathrm{GH}$ se inicie concomitantemente à corticoterapia, para que se possa avaliar qual o verdadeiro papel do $\mathrm{GH}$, preservando o potencial de crescimento dessas crianças.

Durval Damiani

Referência

Simon D, Lucidarme N, Prieur AM, Ruiz JC, Czernichow P. Linear growth in children suffering from juvenile idiopathic arthritis requiring steroid therapy: natural history and effects of growth hormone treatment on linear growth. J Pediatr Endocrinol Metab. 200 I ; 4 Suppl 6: I483-6.

\section{Medicina Zarmaceiutica RESPONSABILIDADE ÉTICA NA PRESCRIÇÃO E A TROCA DE MEDICAMENTOS}

Ao prescrever, o médico considera, com base em conhecimento e responsabilidade, a segurança e eficácia do produto. AANVISA definiu o "erro de medicação" e "reação adversa"'.O primeiro é o evento evitável que, de fato ou potencialmente, pode levar ao uso inadequado de medicamento, que, por sua vez, poderia lesar ou não o paciente. Pode estar relacionado à prática profissional, ao produto usado, procedimento, má 
comunicação na prescrição, rótulos, embalagens, preparação, dispensação, distribuição, monitoramento, etc. "Reação adversa" é qualquer efeito prejudicial ou indesejado após a administração do medicamento, em doses normalmente utilizadas para profilaxia, diagnóstico ou tratamento. Expressa o risco inerente do medicamento, quando usado corretamente. A possibilidade da prevenção é uma das diferenças entre reações adversas e erros de medicação: a primeira é considerada inevitável e o erro de medicação é passível de prevenção. Menos definidas são as ocorrências a partir do momento em que o paciente chega à farmácia. Minoria entre as mais de $50 \mathrm{mil}$ farmácias brasileiras possui farmacêutico, único autorizado por lei a orientar o uso da medicação ou efetuar troca de medicamento por genérico. Esse diálogo entre balconista e paciente pode ser um problema para este último e para o sistema de saúde porque girará em torno de preço, sem consideração à fabricação e ao ato da prescrição médica. Se essa troca resultar em menor eficácia, ineficácia ou reação adversa inesperada, a quem responsabilizar? Não se discute aqui o genérico, intercambiável com o produto-referência. $O$ médico muitas vezes prescreve apenas o princípio ativo, com a consciência de que a troca pode acontecer, caso não oriente de forma contrária, na receita. Todavia, entre marcas e genéricos, há os "bonificados". Estes são comercializados por empresas, muitas vezes, sem compromisso ético, que se beneficiam das deficiências da fiscalização e operam com estratégias comerciais e fiscais questionáveis, oferecendo a balconistas de algumas lojas bonificações variáveis em espécie e valor em troca de vendas. Garantir a qualidade desses produtos - origem da matéria-prima, local de fabricação e adesão às boas práticas laboratoriais - nem sempre é rotina para alguns desses laboratórios, assim como também nem sempre o é farmacovigilância. A questão que fica para os médicos é: o que fazer se um paciente retorna queixando-se de falha terapêutica do medicamento prescrito e substituído pela farmácia? Sendo o responsável pela receita, o seria também pela troca? Muitos profissionais optam por explicitar na receita que "os medicamentos prescritos não devem ser trocados na farmácia”. Assim, o médico pode assumir total responsabilidade pela sua prescrição, não a compartilhando com terceiros desprovidos do devido preparo e movidos por interesses comerciais.

\section{Comentário}

A troca de receita da marca pelo genérico é autorizada pela RDC 135/03 da ANVISA e vale também para as receitas controladas. $E$ a troca por similares é proibida. Similar não pode substituir e nem ser substituído. No ato da dispensação, o profissional farmacêutico - e nunca o balconista - deverá indicar a substituição realizada na prescrição, apor seu carimbo a seu nome e número de inscrição do Conselho Regional de Farmácia, datar e assinar. Vem então a pergunta: aproximadamente 87 mil farmacêuticos trabalhando 8 horas por dia em cerca de 50 mil farmácias cobrem todo o tempo em que todas estão abertas ao público? A legislação para inovadores, genéricos e similares existe e não é a mesma para a comprovação de eficácia e segurança: eles coexistem nas mesmas prateleiras, apesar da lei exigir apenas do genérico que, para ser intercambiável com o de sua referência, exiba os testes de bioequivalência e equivalência farmacêutica realizados por laboratórios acreditados. Os similares não precisam exibir testes para comprovar a mesma eficácia terapêutica da referência. Porém, a exigência de biodisponibilidade relativa concedeu, em 2003, prazos de até II anos para adequação dos similares ${ }^{2,3}$, o que quer dizer que até 2014 esta discussão deixará de existir. Nem tudo é intolerância no mundo.

\section{Vanessa Granato Toscano \\ Vinicius Fontanesi Blum José Roberto Lazzarini Neves}

Referências

I. Agência Nacional de Vigilância Sanitária (ANVISA) - www.anvisa.gov.br 2. http://wwwl .folha.uol.com.br/folha/cotidiano/ult95u l 02734.shtml

3. http://www.anvisa.gov.br/divulga/noticias/2004/07 I 204.htm 